\title{
Patterns of Use of Periodical Literature
}

\begin{abstract}
Questionnaires were distributed to a scientifically selected sample of graduate students in the University of Michigan querying their use of periodical literature in libraries. Tabulated results indicate that this user group utilizes periodicals heavily, that citations are most often sought by subject, that only one or two articles are usually read per library use, and that most such library users are successful in their search for information.
\end{abstract}

T1 HE AUTOMATION OF serial literature records now taking place in many libraries provides a propitious opportunity to enhance the information output of these records for the library user as well as for the librarian. While librarians generally know what information they require of their records, there is no certainty about the information requirements placed upon these same records by library users. This report is the result of a study to determine the patterns of student use of one segment of serial literature, periodicals, in a research library system. ${ }^{1}$ Such a definition of use patterns is one of the essential steps in developing mechanized serial records of value to library staff and patron alike.

The study was conducted at the University of Michigan in the early spring of 1968. A questionnaire was mailed to a sample of students enrolled in the Horace H. Rackham School of Graduate Studies of the university. ${ }^{2}$ It con-

${ }^{1}$ Research funds for this project were provided by the Xerox Corporation Graduate Fellowship in Information Science, and were granted through the Institute of Science and Technology of the University of Michigan.

${ }^{2}$ The details of the sampling procedure, as well as the design of the questionnaire, were developed in consultation with staff members of the Institute for Social Research of the University of Michigan.

Mr. Peterson is Head of the Order and Receiving Department in the Joint University Libraries, Nashville. tained seven basic questions, of which three had one or more subquestions. Most of the questions were constructed to elicit responses based upon the last time the student had actually used periodical literature in a library of the university. ${ }^{3}$ Of the 399 questionnaires that were mailed, 338 , or 85 per cent, were returned and capable of tabulation.

\section{Tabulation and Analysis OF QuestionNAIRES}

Question 1. "How often do you use libraries of the University of Michigan?"

TABLE 1

\begin{tabular}{lr}
\hline \hline Almost never & $3 \%$ \\
A few times a term & $8 \%$ \\
About once a month & $4 \%$ \\
Once in two or three weeks & $7 \%$ \\
About once a week & $31 \%$ \\
Almost every day & $40 \%$ \\
Other & $\mathrm{N}=33 \%$ \\
\hline
\end{tabular}

Every respondent who marked "Other" specified library use of at least once a week. Including this 7 per cent, it must be noted that 78 per cent of the students indicated library use about once a week.

${ }^{3}$ Periodical literature is defined in a note following Question 1 of the Questionnaire (see pages 428-9). The definition is arbitrary and was used only to establish a common understanding of periodical literature for the purposes of this particular study. 
Question 2. "When did you last use periodical literature of a University library?"

TABLE 2

$\begin{array}{lr}\text { Two or three days ago } & 41 \% \\ \text { About a week ago } & 20 \% \\ \text { Two to three weeks ago } & 11 \% \\ \text { About a month ago } & 6 \% \\ \text { More than a month ago } & 6 \% \\ \text { Have not used this term } \quad \mathrm{N} \% \\ & \mathrm{~N}=338\end{array}$

The questionnaire was mailed at such a time as to reflect extensive library use in the given term. The 54 respondents (16 per cent) who indicated that they had not used periodical literature in a University library in the term were not required to complete the questionnaire. Of all respondents (338), 61 per cent used periodical literature about once a week. Of those who reported use of periodical literature in the given term (284), however, the percentage of weekly users climbed to 72 per cent. libraries of the University of Michigan listed on the questionnaire, or to write in a library that was not included on the list. For present purposes, all of the libraries designated in one way or another have been classified according to the administrative organization of the University of Michigan Libraries (Spring 1968).

TABLE 3

\begin{tabular}{lrr}
\hline \hline Medical Science Libraries & 36 & $13 \%$ \\
Science Libraries & 64 & $22.5 \%$ \\
Non-Science Libraries & 62 & $21.5 \%$ \\
Undergraduate Library & 18 & $6 \%$ \\
General (Graduate) Library & 104 & $37 \%$ \\
& $\mathrm{~N}=284$ & \\
\hline
\end{tabular}

Having determined what libraries were used by the respondents, it was then possible to return to Question 2 and consider the frequency of periodical literature use in each of the groups of libraries (Table 4).

Question 4. A. Location and Age of Periodical Literature Used.

TABLE 4

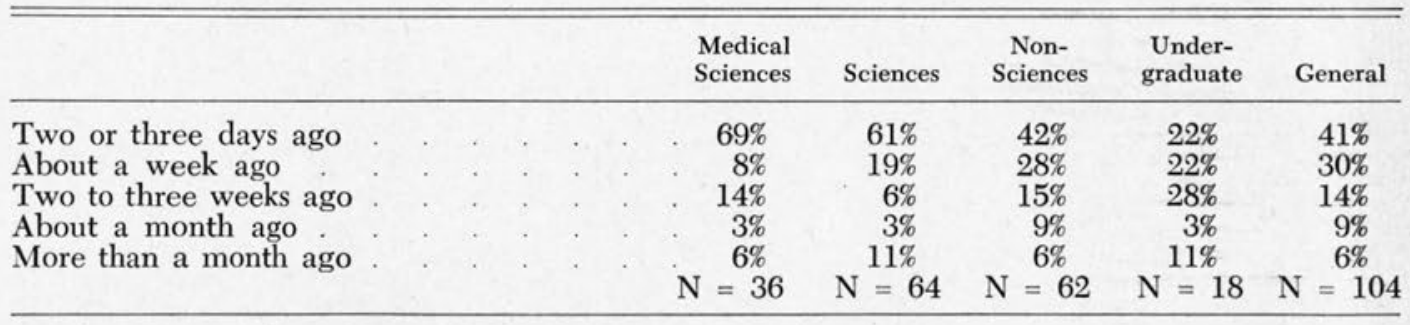

Of the 264 users who indicated they visited a University library about once a week, and of the 204 respondents who used periodical literature about once a week, 190 indicated use of a library and use of periodical literature in that period of time. This represents 56 per cent of all library users, and fully 67 per cent of all users of periodical literature in the given term.

Question 3. "Check the University library which you last visited to use periodical literature."

The respondents were asked either to check one of the twenty-three principal
The students were asked whether they had read current (i.e., less than one year old) or non-current (i.e., more than one year old) literature, and whether this material had been in a reserve reading collection.

TABLE 5

\begin{tabular}{lc}
\hline \hline Reserve reading & $14 \%$ \\
Current literature & $29 \%$ \\
Non-current literature & $35 \%$ \\
Both current and non-current & \\
$\quad$ literature & $16 \%$ \\
No response & $\mathrm{N}=284$ \\
&
\end{tabular}


The division of these results by type of library (Table 6 ) reveals about what might be expected. Current periodical literature is used more in the medical and science libraries, while non-current periodical literature shows substantial use in the general library. rent periodical literature, however, 60 per cent stated that they were using this material specifically for research purposes.

Question 5. "How many articles did you read in the last periodical you used in a University library?"4

TABLE 6

\begin{tabular}{lccccc}
\hline \hline & $\begin{array}{c}\text { Medical } \\
\text { Sciences }\end{array}$ & Sciences & $\begin{array}{c}\text { Non- } \\
\text { Sciences }\end{array}$ & $\begin{array}{c}\text { Under- } \\
\text { graduate }\end{array}$ & General \\
\hline Reserve reading & $3 \%$ & $8 \%$ & $13 \%$ & $22 \%$ & $20 \%$ \\
Current literature & $42 \%$ & $30 \%$ & $31 \%$ & $17 \%$ & $25 \%$ \\
Non-current literature & $33 \%$ & $31 \%$ & $24 \%$ & $33 \%$ & $45 \%$ \\
Both current and non-current literature & $14 \%$ & $25 \%$ & $19 \%$ & $22 \%$ & $10 \%$ \\
No response & $8 \%$ & $6 \%$ & $13 \%$ & $6 \%$ & - \\
& $\mathrm{N}=36$ & $\mathrm{~N}=64$ & $\mathrm{~N}=62$ & $\mathrm{~N}=18$ & $\mathrm{~N}=104$ \\
\hline
\end{tabular}

Question 4. B. Purpose for Which Periodical Literature Was Used.

TABLE 7

\begin{tabular}{lc}
\hline \hline General/professional reading & $20 \%$ \\
Research reading & $65 \%$ \\
Both general/professional and research & $7 \%$ \\
No response & $8 \%$ \\
& $\mathrm{~N}=284$ \\
\hline
\end{tabular}

When these returns are considered by type of library, the percentages are as shown in Table 8.
TABLE 9

\begin{tabular}{lc}
\hline \hline One & $53 \%$ \\
Two & $17 \%$ \\
Several & $24 \%$ \\
Most & $4 \%$ \\
All & $0.3 \%$ \\
Other & $1 \%$ \\
No response & $0.7 \%$ \\
& $\mathrm{~N}=284$ \\
\hline
\end{tabular}

Three students marked "Other." Of these, two indicated that they had skimmed the periodical. One said that

TABLE 8

\begin{tabular}{lcc}
\hline \hline & $\begin{array}{c}\text { Science and } \\
\text { Medical Libraries }\end{array}$ & $\begin{array}{c}\text { All other } \\
\text { Libraries }\end{array}$ \\
\hline General/professional reading & $15 \%$ & $23 \%$ \\
Research reading & $71 \%$ & $63 \%$ \\
Both general/professional and research & $7 \%$ & $7 \%$ \\
No response & $7 \%$ & $7 \%$ \\
& $\mathrm{~N}=100$ & $\mathrm{~N}=184$ \\
\hline
\end{tabular}

Of the 57 respondents ( 20 per cent, Table 7) who indicated that they were doing general/professional reading, 32 also indicated that they were reading current periodical literature. It might have been expected that general reading was being done in the most recent literature. Of all students reading cur- he had read none of the articles. There did not seem to be any significant variation in the responses to this question among the users of the various groups of libraries.

4 "Article" was defined in the questionnaire to include book reviews. See note following Question 3. 
TABLE 10

Number of Articles Read/Purpose for Which Periodical Was Used

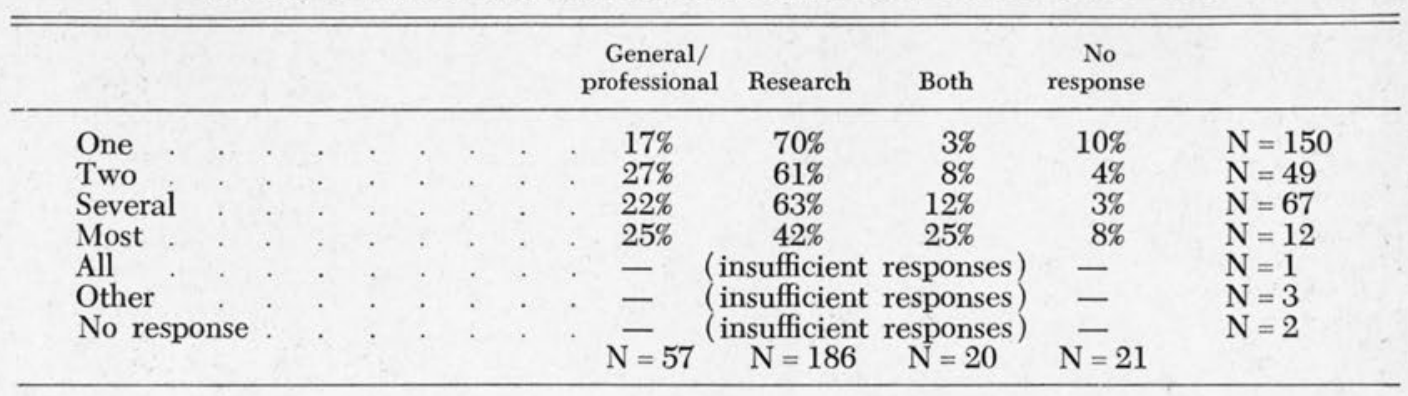

TABLE 11

Number of Articles Read/Location and Age of Periodical

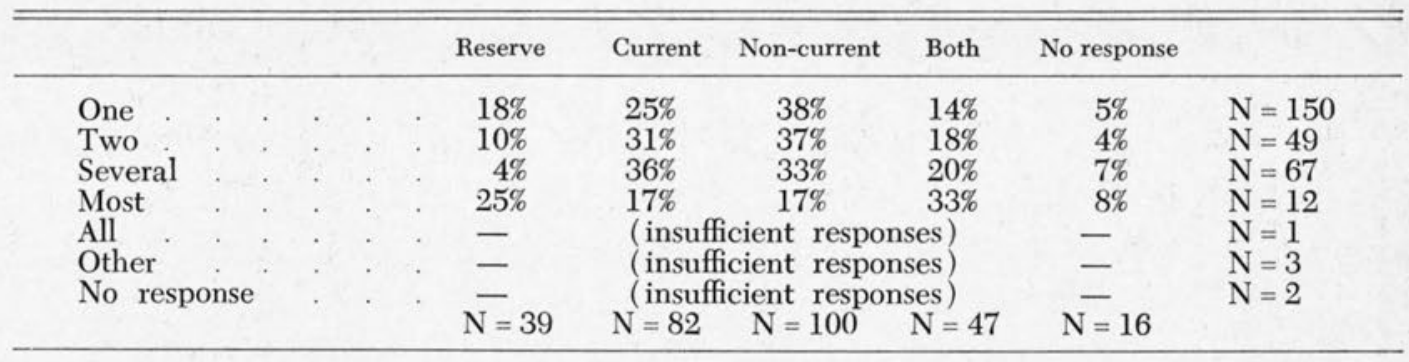

Question 6. Means Used to Determine What Article(s) to Read.

\section{TABLE 12}

Had precise reference to article already $49.3 \%$ Did not have precise reference already $50.0 \%$ No response $0.7 \%$ $\mathrm{N}=284$

Twenty-nine ( 21 per cent) of the 140 students who indicated, as shown in Table 12 , that they already had the precise citation to the article they wished to read also noted that they were reading material in a reserve reading collection.

Exactly 50 per cent (142) of the respondents noted that, prior to using the library resources, they did not have the accurate reference to the material they wished to read. Table 13 shows the means by which these users located the $\operatorname{article}(\mathrm{s})$ they needed.

Of all the respondents surveyed, only 50 (35 per cent, Table 13) neither had the precise reference to the article(s)
TABLE 13

\begin{tabular}{lc}
\hline Used an index & $44 \%$ \\
Used an abstract & $13 \%$ \\
Used both an index and an abstract & $8 \%$ \\
Did not use either an index or an & $35 \%$ \\
abstract & $\mathrm{N}=142$ \\
\hline
\end{tabular}

they wished to read nor found that citation by using an indexing or abstracting service of the library. These $50 \mathrm{stu}$ dents represent 18 per cent of the total respondents (284). Table 14 gives a closer look at this 18 per cent.

TABLE $14^{5}$

Consulted periodicals by publishing society

Consulted $\quad 18 \%$

Consulted periodicals by country of publication

Consulted periodicals by language of publication

Consulted periodicals by period of publication

${ }^{5}$ It was possible to check more than one category in Question 6. 
The ninety-two students who did not have the precise reference to the material they wished to read prior to using

TABLE 15

\begin{tabular}{lc}
\hline $\begin{array}{l}\text { Consulted periodicals by } \\
\text { publishing society }\end{array}$ & $15 \%$ \\
$\begin{array}{l}\text { Consulted periodicals by subject } \\
\text { Consulted periodicals by }\end{array}$ & $65 \%$ \\
$\begin{array}{l}\text { country of publication } \\
\text { Consulted periodicals by } \\
\text { language of publication }\end{array}$ & $4 \%$ \\
$\begin{array}{l}\text { Consulted periodicals by } \\
\text { period of publication }\end{array}$ & $2 \%$ \\
No response & $14 \%$ \\
& $\mathrm{~N}=92$ \\
\hline
\end{tabular}

the library, but who determined that reference by using bibliographical tools of the library, showed a similar pattern in their approach to periodicals, as demonstrated in Table 15.

Tables 16-18 further describe the patterns of use of the fifty respondents who neither had the needed reference nor used an index or abstract, and contrast these findings with the use patterns of the other two groups, i.e., those who already had the reference, and those who used an index and/or abstract to determine the reference.

TABLE 16

Location and Age of Periodical Literature Used

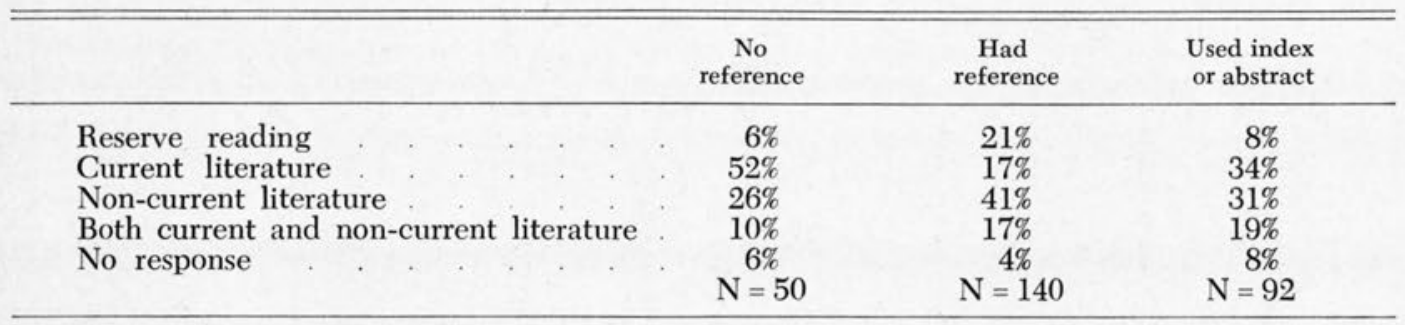

TABLE 17

Purpose for Which Periodical Literature Was Used

\begin{tabular}{lccc}
\hline \hline & $\begin{array}{c}\text { No } \\
\text { reference }\end{array}$ & $\begin{array}{c}\text { Had } \\
\text { reference }\end{array}$ & $\begin{array}{c}\text { Used index } \\
\text { or abstract }\end{array}$ \\
\hline $\begin{array}{l}\text { General/professional reading } \\
\begin{array}{l}\text { Research reading } \\
\text { Both general/professional } \\
\text { and research reading }\end{array}\end{array} \quad 38 \%$ & $13 \%$ & $21 \%$ \\
No response & $44 \%$ & $69 \%$ & $71 \%$ \\
& $8 \%$ & $9 \%$ & $4 \%$ \\
& $\mathrm{~N}=50$ & $\mathrm{~N}=140$ & $\mathrm{~N}=92$ \\
\hline
\end{tabular}

TABLE 18

Number of Articles Read

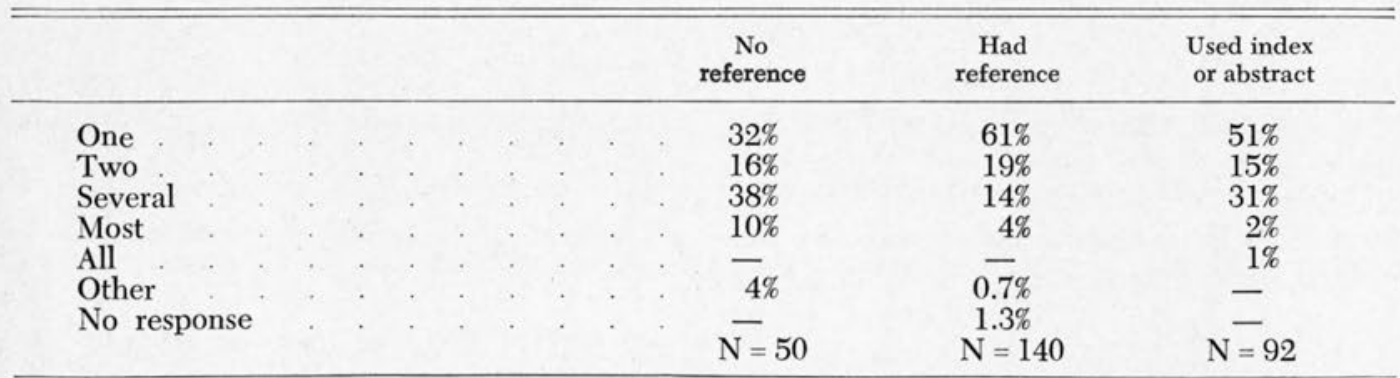


Question 7. Success in Finding Periodical Literature.

TABLE 19

Respondents who found the article for which they were looking Respondents who did not find the article for which they were looking $80.3 \%$ No response

Respondents who indicated that they were unable to find the article or the periodical for which they were looking were asked what information regarding the material they were able to find. Table 20 shows the results.

TABLE 20

$\begin{array}{lc}\text { Periodical was in the library being used, } \\ \text { but was unavailable } & 44 \% \\ \text { Periodical was in another library } & 17 \% \\ \text { Periodical was not in any library } & 19 \% \\ \text { of the University } & 10 \% \\ \text { Other information } & 8 \% \\ \text { No information } & 2 \% \\ \text { No response } & \mathrm{N}=48\end{array}$

Seventy-three per cent of those students who did not find the periodical for which they were looking were searching for a non-current publication. Forty-four per cent of these respondents had the precise reference to the article they wished to consult, and fully 67 per cent of these students indicated that they used periodical literature in a University library at least once a week.

\section{SUMMARY}

The purpose of this project was to define the patterns of use of periodical litterature as demonstrated by graduate students working in a research library system. Patterns, even when based upon measured responses to actual incidents of use, primarily serve as guides and, as such, only indicate general trends. The following patterns are those which are clearly evident from the results of this study.
I

Periodical literature receives substantial use. Eighty-four per cent of the students surveyed indicated use of periodical literature in the given school term. Sixty per cent indicated use of periodical literature at least once a week. Moreover, periodical literature is heavily used by the students who are the most frequent and steady patrons of University libraries. Thus, the significance of periodical literature for graduate students is demonstrated on both an absolute and a proportional scale of use.

Periodical literature seems no less important for nonscience libraries than it is for the libraries related to the several sciences. The respondents who indicated that they used periodical literature at least once a week encompass 79 per cent of all users of science libraries, and 68 per cent of all users of nonscience libraries.

\section{II}

The subject approach to periodical literature is the dominant approach used by graduate students. This is true for the students who did not have the precise reference to the article they wished to read, as well as for the students who located the reference to their needed article through an index or abstracting service. The preference for the subject approach was so strong it would indicate that other indexing schemes, e.g., indexing by publishing society, language, period, country, etc., ought to be employed only in the most rare and specialized instances. ${ }^{6}$

\footnotetext{
${ }^{6}$ Of course, student preference for the subject approach may be due to the fact that little service is presently offered through other bibliographical avenues. Further conclusions about these other approaches should be made only after our library patrons have had considerable experience using these other means. See G. A. Miller, "Measuring User Needs and Preferences," Intrex Report of a Planning Conference on Information Transfer Experiments (Cambridge: MIT Press, 1965), p. 56.
} 


\section{QUESTIONNAIRE}

1. How often do you use libraries of the University of Michigan?

( ) Almost never
( A few times a term
( ) About once a month
Once in 2 to 3 weeks

$\begin{array}{ll}\text { ( ) } & \text { About once a week } \\ \text { ( ) Almost every day } \\ \text { ( ) Other (specify) } \ldots \ldots \ldots \ldots \ldots \ldots\end{array}$

N.B. PERIODICAL LITERATURE in the following questions refers to publications issued at more or less regular intervals. These publications usually contain articles by several contributors. PERIODICAL LITERATURE includes magazines, journals, annual reports, and society proceedings and transactions. EXCLUDED are newspapers and government documents.

2. When did you LAST use periodical literature of a University library?
( ) Two or three days ago
( ) About a week ago
( ) About two or three weeks ago
( ) About a month ago
( ) More than a month ago
( ) Have not used periodical literature of a University library this term

If you have not used periodical literature of a University library this term, you need not answer the remaining questions. Please return this questionnaire in the enclosed envelope.

3. Check the University library which you LAST visited to use periodical literature.

( ) Architecture
( Asia (in General Lib.)
( ) Business Administration
baseau of Government (in
( ) Chemistry-Pharmacy Bldg.)
( ) Dentistry
( ) Education (in Undergraduate)
Engineering-Transportation
(in Undergraduate)
( ) Fine Arts
( ) Institute of Science and
Technology

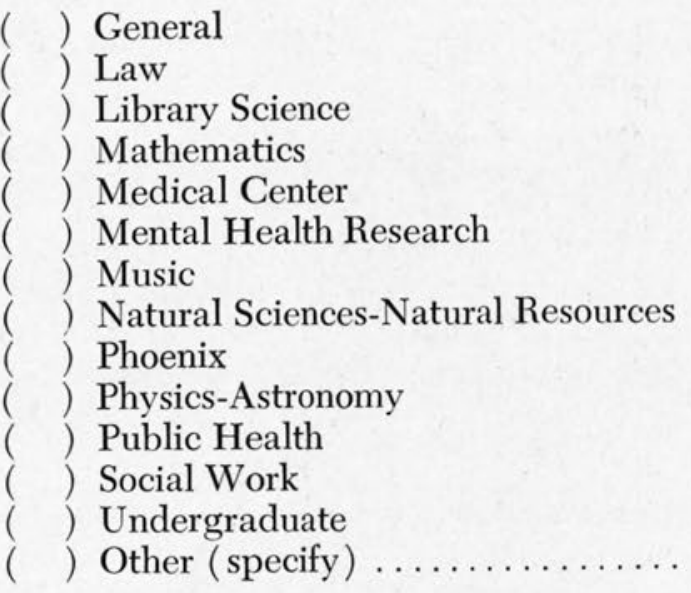

N.B. ARTICLES in the following questions include book reviews. 
4. When you LAST visited a University library to use periodical literature, were you looking for
A. ( ) Periodical literature in a reserve reading collection?
) Current periodical literature (one year old or less)?
( ) Non-current periodical literature (more than one year old)?
B. ( ) Articles of a general professional or informative nature?
( ) Articles for some definite research or scholarly use?

5. How many articles did you read in the LAST PERIODICAL you used in a University library?

( ) One, ( ) Two, ( ) Several, ( ) Most, ( ) All, ( ) Other ......

6. When you LAST visited a University library to use periodical literature, which of the following approaches did you use to determine what article(s) you wished to read?

( ) Consulted periodicals published by a society in which I am a member or interested.

) Consulted periodicals in my subject field.

) Consulted periodicals published in the country of my interest.

) Consulted periodicals published in the language of my interest.

( ) Consulted periodicals published in the chronological period of my interest.

If you checked ANY of the above, did you at any time use the table of contents or the index of the periodical? ( ) Yes, ( ) No.

( ) Consulted one or more general index (indexing several periodicals).

( ) Consulted one or more abstracting periodicals.

( ) Already had the reference from some other source.

( ) Other (specify) $\ldots \ldots \ldots \ldots \ldots \ldots \ldots \ldots \ldots \ldots \ldots \ldots \ldots \ldots \ldots \ldots \ldots$

7. When you LAST visited a University library to use periodical literature, were you able to find the periodical for which you were looking in the library you were using? ( ) Yes, ( ) No.

If NO, what information about the periodical you wished to use were you able to find out? (check all that apply).

) It was in the library I was using, but was not available.

( It was not in the library I was using, but was in some other library of the University.

It was not available in any University library.

No information.

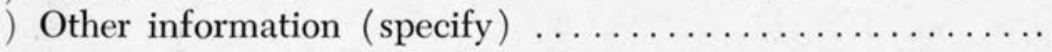

In the space below, please add any additional comments about library service of the University as you have found it in relation to periodical literature.

Thank you. 


\section{III}

The majority of users of periodical literature read only one article, and 70 per cent of the respondents read not more than two articles. What is more, 70 per cent of those who read one article and 61 per cent of those who read two articles were using periodical literature for research purposes. These results would indicate that indexing or otherwise controlling periodicals by broad categories will not be of substantial help to most users. Periodical literature is generally consulted for rather specific purposes, and specific articles are usually read.

The students who read only one or two articles in a given periodical showed some preference for non-current numbers. Among graduate students reading one article, thirteen percentage points separate the users of current literature from the users of non-current periodical literature. Only six percentage points separate the same users among those students reading two articles. If nothing else, this evidence should encourage librarians to reduce the time lag from the appearance of periodical literature to the appearance of the several indexes.

\section{IV}

The overwhelming number of library users among graduate students approach the use of periodical literature well prepared to find the article which they need. Nearly half of the respondents already had the precise reference to the article they needed before they began to use library materials and aids.

Sixty-five per cent of the respondents who did not have the reference prior to using the library indicated that they found the needed reference in the available indexes and abstracting services. This is an encouraging report. It demonstrates that if collections of periodical literature were evenly and adequately indexed and if these indexes were up to date, many library users would be quite self-sufficient in their approach to this literature.

Of course, this does not consider the question of whether or not the information needs of these students would have been better met by that bulk of periodical literature, found in every library, which is neither indexed nor abstracted. Yet the evidence shows that efforts to increase and accelerate indexing services are proper and rewarding endeavors.

Only eleven respondents indicated that, at the end of their search for a periodical article, they had found neither the article nor any appreciable information regarding it. This is equal to less than 1 per cent of the total respondents, and indicates a very large number of satisfied users of periodical literature.

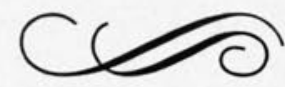

